\title{
Sensitivity analysis of the GTN damage parameters at different temperature for dynamic fracture propagation in X70 pipeline steel using neural network
}

\author{
Abdelmoumin Ouladbrahim, Idir Belaidi \\ Department of Mechanical Engineering, University M'bamed Bougara Boumerdes, LEMI Laboratory, 35000 Boumerdes, \\ Algeria. \\ moumindoc@gmail.com; https://orcid.org/0000-0003-4729-298X \\ idir.belaidi@gmail.com; https://orcid.org/0000-0003-3160-1135
}

Samir Khatir, Magd Abdel Wahab

Soete Laboratory, Faculty of Engineering and Architecture, Ghent University, Technologiepark Zwijnaarde 903, B-9052, Zwijnaarde, Belgium;

Khatir.samin@hotmail.fr; https://orcid.org/0000-0002-8101-3633

Magd.AbdelWahab@UGent.be; https://orcid.org/0000-0002-3610-865X

\section{Erica Magagnini, Roberto Capozucca}

DICE A, Structural Section, Polytechnic University of Marche, Italy

ABSTRACT. In this paper, the initial and maximum load was studied using the Finite Element Modeling (FEM) analysis during impact testing (CVN) of pipeline X70 steel. The Gurson-Tvergaard-Needleman (GTN) constitutive model has been used to simulate the growth of voids during deformation of pipeline steel at different temperatures. FEM simulations results used to study the sensitivity of the initial and maximum load with GTN parameters values proposed and the variation of temperatures.

Finally, the applied artificial neural network (ANN) is used to predict the initial and maximum load for a given set of damage parameters X70 steel at different temperatures, based on the results obtained, the neural network is able to provide a satisfactory approximation of the load initiation and load maximum in impact testing of X70 Steel.

KEYwORDS. Steel X70; Impact test (CVN); GTN parameters; FEM; Artificial neural network.

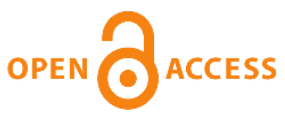

Citation: Ouladbrahim, A., Belaidi, I, Khatir, S., Wahab, M. A., Magagnini, E., Capozucca, R., Sensitivity analysis of the GTN damage parameters at different temperature for dynamic fracture propagation in X70 pipeline steel using neural network, Frattura ed Integrità Strutturale, 58 (2021) 442-452.

Received: 27.08 .2021

Accepted: 04.09 .2021

Published: 01.10 .2021

Copyright: (C) 2021 This is an open access article under the terms of the CC-BY 4.0, which permits unrestricted use, distribution, and reproduction in any medium, provided the original author and source are credited. 


\section{INTRODUCTION}

$\mathrm{T}$ he importance in the design of the current pipelines is the sufficient resistance of steels against fractures and ductile rupture of the pipelines should be avoided and their catastrophic consequences with the initiation of the rupture and the propagation of the fracture of the pipeline, while this requires a value of the minimum toughness of the steel necessary to arrest a long-lasting ductile fracture.

The mechanical characterizations deduced from tensile testing in the pipeline manufacturing laboratory may be insufficient because breaks can be obtained below the yield strength under normal and special conditions rendering the material in a brittle state. The impact test is a main complement to the tensile test.

The impact bending test or the impact test on a notched Charpy specimen is intended to measure the resistance of a material to sudden rupture.

The impact test represented by The Charpy V-Notch (CVN) (ASTM International) [1] is used to determine the fracture value of the toughness of a considerable material in the frame that it is an easy and more economical method to perform experiments.

The high cost of large-scale experimental campaigns has driven the development of more economical laboratory-scale tests such as the well-known Charpy V-Notch (CVN) impact test, Drop Weight Tear Test (DWTT) [2]and more recently the Dynamic Tear Test (DT3) [3]. For modern pipelines with a wall thickness reaching over 20mm, the CVN has a relatively small standard specimen size with a cross section of $10 \mathrm{~mm} \times 10 \mathrm{~mm}$ [4]. In addition, limited by the test conditions, the results of the Charpy impact test will be affected by certain factors, which have been investigated by many of the researchers. It is also of great research value to transform non-standard test results into standard results. $\mathrm{Li}$ [5]studied the influence of the radius of the striker on the energy absorbed by the impact of X80 steel for pipelines; Madhusudhan[6] presented the variation of energy absorbed by changing the pendulum speeds of $5 \mathrm{~m} / \mathrm{s}, 6 \mathrm{~m} / \mathrm{s}, 7 \mathrm{~m} / \mathrm{s}$ and $9 \mathrm{~m} / \mathrm{s}$ of maraging steel 300 using Abaqus software. For X70 pipeline steel, there is a lack of comprehensive and systematic analysis of factors influencing the results of Charpy impact testing; so the corresponding damage models can be validated and / or calibrated to be implemented in more complex simulations. The Gurson-Tvergaard-Needleman (GTN) [7] damage model is well-known and widely applied and it is used to simulate dynamic ductility fracture propagation [8]. Due to the limited parameter set in this model, it is often adopted in the industry field.

In this article, the application of the GTN damage model for the dynamic propagation of fractures in the Charpy test case is studied and the influence of the damage parameters on the initial and maximum fracture load will be quantified. At failure are applied to a high strength pipe material, namely X70 through a numerical study of a CVN impact experiment.

A sensitivity analysis of the GTN damage constants is carried out to evaluate their influence on the initial and maximum load expected at failure. To analyze the simulation data obtained, machine learning approaches are applied and represented by an artificial neural network in order to identify the relative influence of the values of the GTN parameters and in temperature change on the initial and maximum load of the rupture.

The potential predictive capacity of our model is tested by analyzing the outputs of our neural network for the proposed GTN parameter sets.

\section{FINITE ELEMENT MODEL}

$\mathrm{F}$ $\mathrm{E}$ analysis of tensile test for base metal is performed using commercially available ABAQUS software; the Charpy tensile and impact part is modeled as deformable.

A 3D solid finite element model was implemented with the aim to reproduce the laboratory scale fracture toughness experiment $(\mathrm{CVN})$. The ABAQUS/Explicit solver permitted the application of the GTN damage model for the simulation of the dynamic propagation of fractures.

The geometry was created based on the standard dimensions of the specimen as shown in the Fig. 1 below. In each model, the mesh was created using linear 8 node brick elements with reduced integration. The mesh size is of significant importance when the GTN damage model is implemented [9]. In this study, an element size of $0.25 \mathrm{~mm}$ was used (see Fig. 1).

The condition of zero penetration between the hammer and the test specimen has been implemented [10]. In addition, friction has been taken into account using a penalty function with a coefficient of friction equal to 0.1. Due to the impact load in the CVN, the acceleration and, as consequence, force measurements can show pronounced oscillations. Therefore, the velocity data was extracted and derived to obtain acceleration and force data. This method reduced the presence of oscillations and made it possible to construct the force-displacement curves for each respective simulation. 
The Charpy Impactor impact test is modeled as discrete rigid. The assigned physical material properties are shown in Tab. 1. Current stress and Charpy impact models are subjected to plastic strain, therefore plasticity material properties at different temperatures $\left(-20,-10,0\right.$ and $\left.20^{\circ} \mathrm{C}\right)$ for base metal are assigned using tensile test result data as shown in Fig. 2.
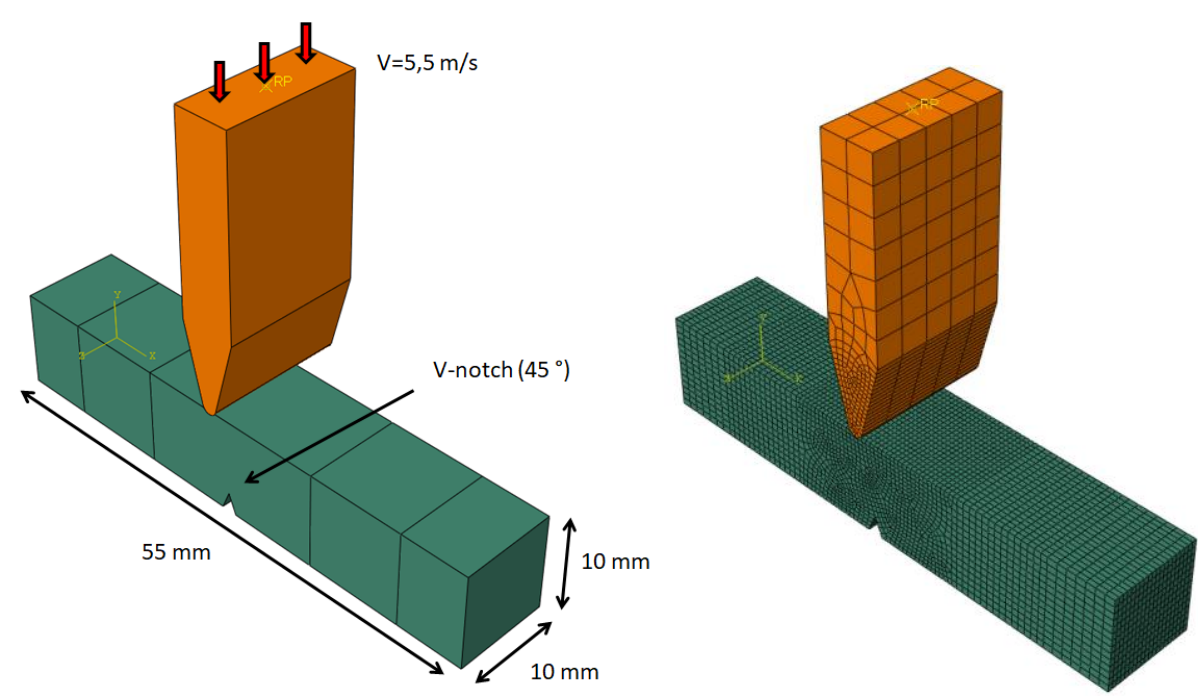

Figure 1: A scheme of impact test specimen dimension and mesh used in finite element simulation.

\begin{tabular}{cc}
\hline Young's modulus $210 \mathrm{GPa}$ & $E=210 \mathrm{GPa}$ \\
Poisson's ratio & $v=0.3$ \\
Isotropic hardening & $\sigma_{\text {yld }}=485 \mathrm{MPa}$ \\
& $K=795 \mathrm{MPa}$ \\
& $n=0.13$ \\
& $D=55$ \\
Strain rate effect & $P=5$ \\
\hline
\end{tabular}

Table 1: Mechanical properties for X70 grade steels [11].

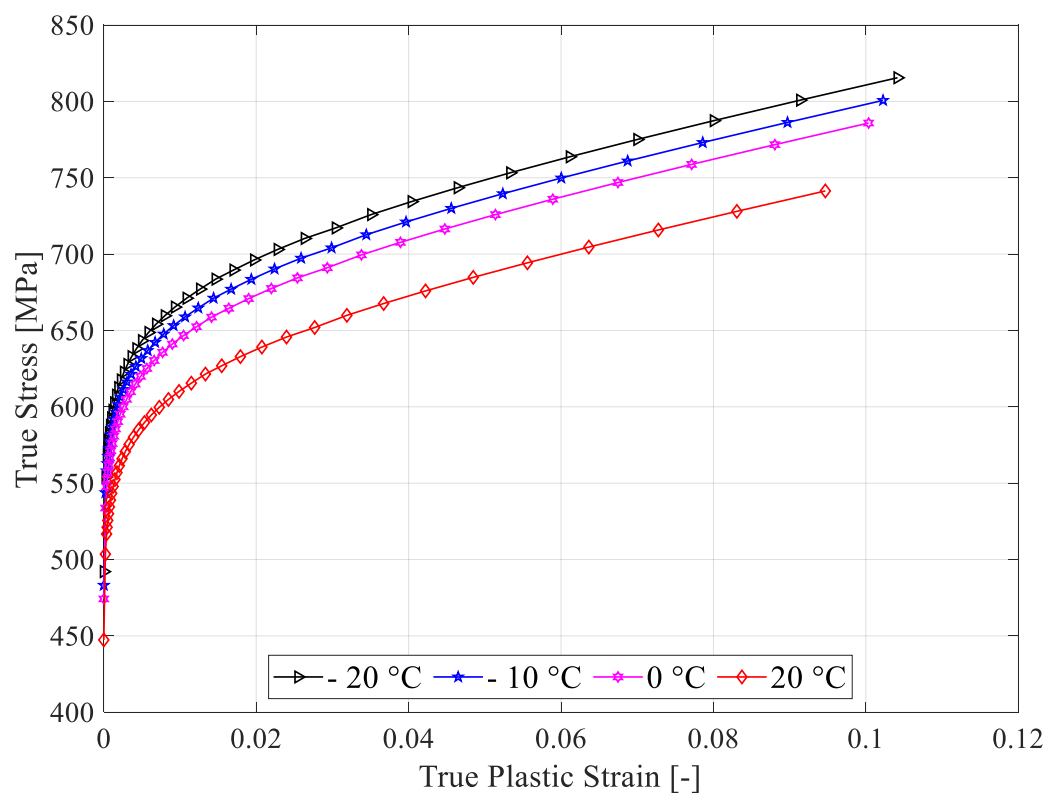

Figure 2: True stress Vs True strain at different temperatures.

The thermophysical properties of API 5L X70 steel using for this simulation is shown in Tab. 2. 


\begin{tabular}{cccc}
\hline Material & $\begin{array}{c}\text { Conductivity } \\
\left(\mathrm{W} / \mathrm{m}^{\circ} \mathrm{C}\right)\end{array}$ & $\begin{array}{c}\text { Specific heat } \\
\left(\mathrm{J} / \mathrm{kg}^{\circ} \mathrm{C}\right)\end{array}$ & $\begin{array}{c}\text { Thermal expansion } \\
\left(\mathrm{u} \mathrm{m} / \mathrm{m}^{\circ} \mathrm{C}\right)\end{array}$ \\
API X70 & 52 & 420 & 8.5 \\
\hline
\end{tabular}

Table 2: Thermophysical properties of API grade X70 steel [12].

\begin{tabular}{|c|c|c|c|c|c|c|c|c|c|c|c|c|}
\hline Temperature & Parameters & $q 1$ & $q^{2}$ & $\varepsilon_{n}$ & $f n$ & $f_{c}$ & Parameters & $q 1$ & $q^{2}$ & $\varepsilon_{n}$ & $f n$ & $f_{c}$ \\
\hline \multirow{38}{*}{$\begin{array}{l}\text { Step1:20 }{ }^{\circ} \mathrm{C} \\
\text { Step2: } 0^{\circ} \mathrm{C} \text {; } \\
\text { Step3: }-10^{\circ} \mathrm{C} \text {; } \\
\text { Step4: }-20^{\circ} \mathrm{C} \text {. }\end{array}$} & 1 & 1.5 & 1 & 0.3 & 0.012 & 0.0002 & 39 & 1.43 & 0.95 & 0.5 & 0.02 & 0.0042 \\
\hline & 2 & 1.47 & 1 & 0.3 & 0.012 & 0.0002 & 40 & 1.5 & 0.95 & 0.5 & 0.02 & 0.0042 \\
\hline & 3 & 1.43 & 1 & 0.3 & 0.012 & 0.0002 & 41 & 1.47 & 0.95 & 0.5 & 0.02 & 0.0042 \\
\hline & 4 & 1.4 & 1 & 0.3 & 0.012 & 0.0002 & 42 & 1.4 & 0.95 & 0.5 & 0.02 & 0.0042 \\
\hline & 5 & 1.5 & 0.975 & 0.3 & 0.012 & 0.0002 & 43 & 1.43 & 1 & 0.5 & 0.02 & 0.0042 \\
\hline & 6 & 1.5 & 0.95 & 0.3 & 0.012 & 0.0002 & 44 & 1.43 & 0.975 & 0.5 & 0.02 & 0.0042 \\
\hline & 7 & 1.5 & 0.925 & 0.3 & 0.012 & 0.0002 & 45 & 1.43 & 0.925 & 0.5 & 0.02 & 0.0042 \\
\hline & 8 & 1.5 & 1 & 0.4 & 0.012 & 0.0002 & 46 & 1.43 & 0.95 & 0.3 & 0.02 & 0.0042 \\
\hline & 9 & 1.5 & 1 & 0.5 & 0.012 & 0.0002 & 47 & 1.43 & 0.95 & 0.4 & 0.02 & 0.0042 \\
\hline & 10 & 1.5 & 1 & 0.7 & 0.012 & 0.0002 & 48 & 1.43 & 0.95 & 0.7 & 0.02 & 0.0042 \\
\hline & 11 & 1.5 & 1 & 0.3 & 0.016 & 0.0002 & 49 & 1.43 & 0.95 & 0.5 & 0.012 & 0.0042 \\
\hline & 12 & 1.5 & 1 & 0.3 & 0.02 & 0.0002 & 50 & 1.43 & 0.95 & 0.5 & 0.016 & 0.0042 \\
\hline & 13 & 1.5 & 1 & 0.3 & 0.024 & 0.0002 & 51 & 1.43 & 0.95 & 0.5 & 0.024 & 0.0042 \\
\hline & 14 & 1.5 & 1 & 0.3 & 0.028 & 0.0002 & 52 & 1.43 & 0.95 & 0.5 & 0.028 & 0.0042 \\
\hline & 15 & 1.5 & 1 & 0.3 & 0.012 & 0.0022 & 53 & 1.43 & 0.95 & 0.5 & 0.02 & 0.0002 \\
\hline & 16 & 1.5 & 1 & 0.3 & 0.012 & 0.0042 & 54 & 1.43 & 0.95 & 0.5 & 0.02 & 0.0022 \\
\hline & 17 & 1.5 & 1 & 0.3 & 0.012 & 0.005 & 55 & 1.43 & 0.95 & 0.5 & 0.02 & 0.005 \\
\hline & 18 & 1.5 & 1 & 0.3 & 0.012 & 0.0062 & 56 & 1.43 & 0.95 & 0.5 & 0.02 & 0.0062 \\
\hline & 19 & 1.5 & 1 & 0.3 & 0.012 & 0.008 & 57 & 1.43 & 0.95 & 0.5 & 0.02 & 0.008 \\
\hline & 20 & 1.47 & 0.975 & 0.4 & 0.016 & 0.0022 & 58 & 1.4 & 0.925 & 0.7 & 0.024 & 0.005 \\
\hline & 21 & 1.5 & 0.975 & 0.4 & 0.016 & 0.0022 & 59 & 1.5 & 0.925 & 0.7 & 0.024 & 0.005 \\
\hline & 22 & 1.43 & 0.975 & 0.4 & 0.016 & 0.0022 & 60 & 1.47 & 0.925 & 0.7 & 0.024 & 0.005 \\
\hline & 23 & 1.4 & 0.975 & 0.4 & 0.016 & 0.0022 & 61 & 1.43 & 0.925 & 0.7 & 0.024 & 0.005 \\
\hline & 24 & 1.47 & 1 & 0.4 & 0.016 & 0.0022 & 62 & 1.4 & 1 & 0.7 & 0.024 & 0.005 \\
\hline & 25 & 1.47 & 0.95 & 0.4 & 0.016 & 0.0022 & 63 & 1.4 & 0.975 & 0.7 & 0.024 & 0.005 \\
\hline & 26 & 1.47 & 0.925 & 0.4 & 0.016 & 0.0022 & 64 & 1.4 & 0.95 & 0.7 & 0.024 & 0.005 \\
\hline & 27 & 1.47 & 0.975 & 0.3 & 0.016 & 0.0022 & 65 & 1.4 & 0.925 & 0.3 & 0.024 & 0.005 \\
\hline & 28 & 1.47 & 0.975 & 0.5 & 0.016 & 0.0022 & 66 & 1.4 & 0.925 & 0.4 & 0.024 & 0.005 \\
\hline & 29 & 1.47 & 0.975 & 0.7 & 0.016 & 0.0022 & 67 & 1.4 & 0.925 & 0.5 & 0.024 & 0.005 \\
\hline & 30 & 1.47 & 0.975 & 0.4 & 0.012 & 0.0022 & 68 & 1.4 & 0.925 & 0.7 & 0.012 & 0.005 \\
\hline & 31 & 1.47 & 0.975 & 0.4 & 0.02 & 0.0022 & 69 & 1.4 & 0.925 & 0.7 & 0.016 & 0.005 \\
\hline & 32 & 1.47 & 0.975 & 0.4 & 0.024 & 0.0022 & 70 & 1.4 & 0.925 & 0.7 & 0.02 & 0.005 \\
\hline & 33 & 1.47 & 0.975 & 0.4 & 0.028 & 0.0022 & 71 & 1.4 & 0.925 & 0.7 & 0.028 & 0.005 \\
\hline & 34 & 1.47 & 0.975 & 0.4 & 0.016 & 0.0002 & 72 & 1.4 & 0.925 & 0.7 & 0.024 & 0.0002 \\
\hline & 35 & 1.47 & 0.975 & 0.4 & 0.016 & 0.0042 & 73 & 1.4 & 0.925 & 0.7 & 0.024 & 0.0022 \\
\hline & 36 & 1.47 & 0.975 & 0.4 & 0.016 & 0.005 & 74 & 1.4 & 0.925 & 0.7 & 0.024 & 0.0042 \\
\hline & 37 & 1.47 & 0.975 & 0.4 & 0.016 & 0.0062 & 75 & 1.4 & 0.925 & 0.7 & 0.024 & 0.0062 \\
\hline & 38 & 1.47 & 0.975 & 0.4 & 0.016 & 0.008 & 76 & 1.4 & 0.925 & 0.7 & 0.024 & 0.008 \\
\hline
\end{tabular}

Table 3: GTN parameters used in the simulation. 
The finite element analysis of the impact test specimen was performed using the mesh size of $0.2 \mathrm{~mm}$ around the notch area. The simulation parameters at different temperatures of $\left(-20,-10.0\right.$ and $\left.20^{\circ} \mathrm{C}\right)$ are shown in Tab. 3 .

The GTN damage model parameters are:

- $\quad q 1, q 2$ and $q 3$ : related to the strengthening of the matrix material.

- $\quad \varepsilon_{n}$ and $S_{n}$ : mean equivalent plastic strain and the standard deviation.

- $\quad f n, f c$ : volume fraction of the critical voids.

- $f_{\mathrm{F}}$ : the failure volume fraction of the material failure.

- In this work we consider that these parameters are fixed $s_{n}=0.1$, and $f_{\mathrm{F}}=0.18$.

\section{Test Material}

The investigation of our study concerns manganese carbon steel used for the transport of hydrocarbons (gas and oil) under a working pressure of 70 bars with the name API 5L X70. The material meets the specification imposed by the standard API 5L [13]. Tab. 4 shows the chemical composition of the steel used.

\begin{tabular}{cccccc}
\hline $\mathrm{C}$ & $\mathrm{Mn}$ & $\mathrm{Si}$ & $\mathrm{Cr}$ & $\mathrm{Ni}$ & $\mathrm{Mo}$ \\
0.125 & 1.680 & 0.270 & 0.051 & 0.040 & 0.021 \\
$\mathrm{~S}$ & $\mathrm{~S}$ & $\mathrm{Cu}$ & $\mathrm{Ti}$ & $\mathrm{Nb}$ & $\mathrm{Al}$ \\
0.005 & 0.005 & 0.045 & 0.003 & 0.033 & 0.038 \\
\hline
\end{tabular}

Table 4: Chemical composition requirement for analyzes (API 5L X70; wt \%; Fe is bal.).

\section{Effect of specimen at different temperatures}

Several impact tests were performed at different temperatures and the specimens were cooled using a special type of cooler designed to provide cooling temperatures down to $-60^{\circ} \mathrm{C}$.

These tests are carried out on a Charpy machine. We have carried out tests $[-20 \mathrm{C} ;+20 \mathrm{C}]$ at the ALFAPIPE mechanical test laboratory, in accordance with API 5L X70.

The dimensions of the test piece are given in Fig. 1, the resilience test was carried out on standard CVN $10 * 10$ test specimens, the geometry of which according to API $5 \mathrm{~L}$.

From Tab. 5, it is shown that as the temperature of the specimen keeps high values, the corresponding impact energy required for failure increases rapidly due to the steel being moved to the ductile zone. At high temperatures, while at low temperatures, steel behaves like a brittle material which requires quite a bit of energy to fracture.

\begin{tabular}{|c|c|c|c|c|c|}
\hline & \multirow{2}{*}{$t,{ }^{\circ} \mathrm{C}$} & \multicolumn{3}{|c|}{ Energy $\left(\mathrm{J} / \mathrm{cm}^{2}\right)$} & \multirow{2}{*}{$\frac{\text { Energy }\left(\mathrm{J} / \mathrm{cm}^{2}\right)}{\text { Average }(1,2,3)}$} \\
\hline & & Test 1 & Test 2 & Test 3 & \\
\hline \multirow{4}{*}{$\begin{array}{l}\text { Base metal } \\
\text { (BM) }\end{array}$} & 20 & 262.8 & 254.1 & 266.5 & 261.13 \\
\hline & 0 & 248 & 242 & 238 & 242.67 \\
\hline & -10 & 216 & 210 & 210 & 212 \\
\hline & -20 & 206 & 205 & 203 & 204.67 \\
\hline
\end{tabular}

Table 5: Macro-characteristics of Charpy specimens cut from X70 pipe steel tested for impact toughness-Experimental.

\section{RESULTS}

\section{Simulated Load-displacement/ time curve}

7 ypical load Vs displacement/time curve obtained from the FEM simulation is shown in Fig. 3. Similar to the analysis of the experimental results, the load-displacement curve is divided into three parts: I-before the general yield point, II-between the general yield point and the peak point, and III-after the maximum point till the final fracture. All points are marked in Fig. 3.

It can be seen in Fig. 3 that the load increases linearly with the displacement in Part I. between the general yield point and the peak point the material starts to be deformed plastically. In Part III, the crack propagates and the load decreases to end of impact and the final separation is observed. All results at different temperatures and GTN parameters values of FEM simulated load values are summarized in Tab. 6. 


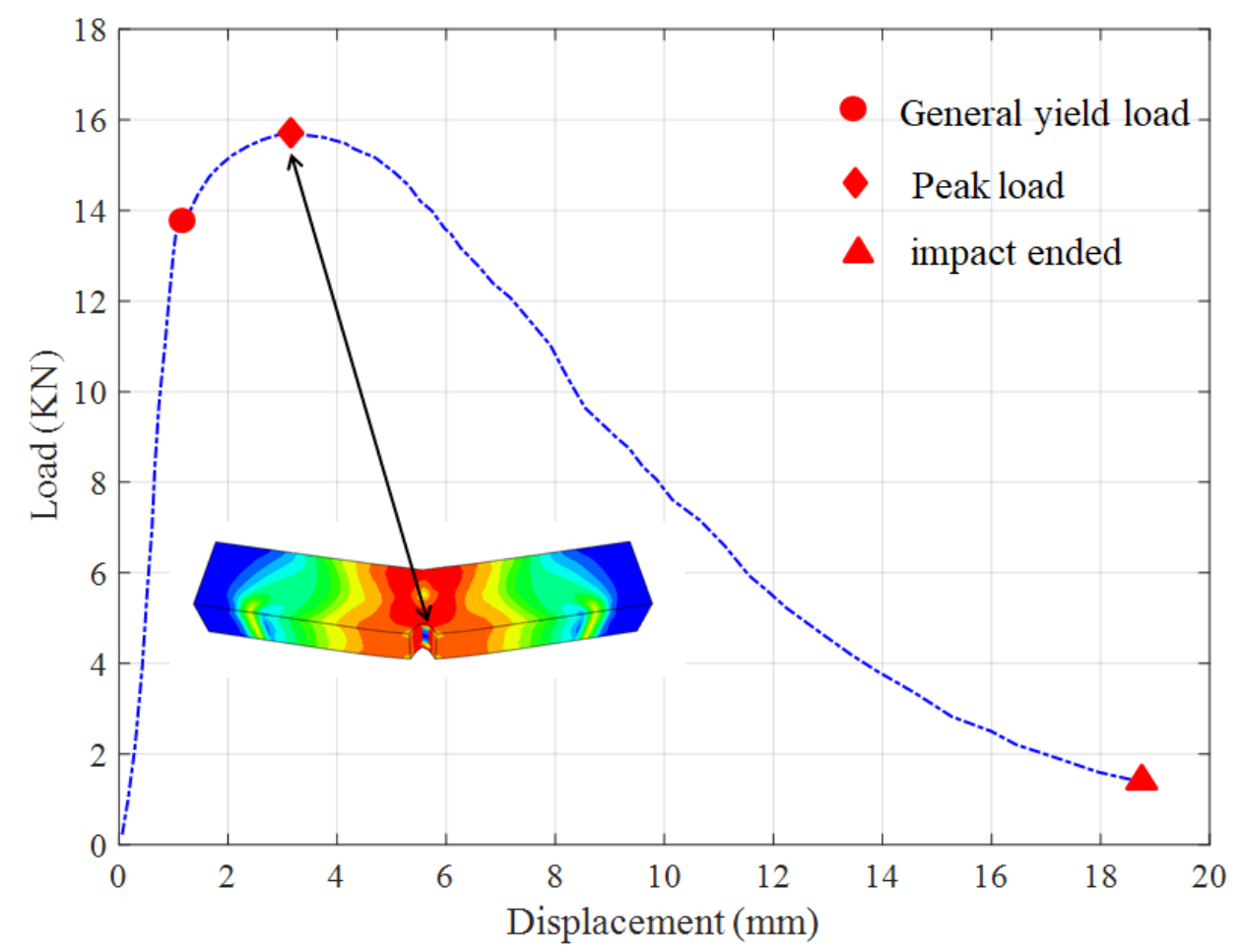

Figure 3: The simulated load-displacement curve, Impact testing-X70.

\begin{tabular}{cccccccccc}
\hline & & \multicolumn{3}{c}{ Experiment } & \multicolumn{3}{c}{ FEM simulated } \\
$\begin{array}{c}\text { Material } \\
\text { Specimen }\end{array}$ & Temperature & $\begin{array}{c}\text { General yield } \\
\text { Min-Max (kN) }\end{array}$ & $\begin{array}{c}\text { Peak load } \\
\text { Min-Max (kN) }\end{array}$ & $\begin{array}{c}\text { General yield } \\
\text { Min-Max (kN) }\end{array}$ & $\begin{array}{c}\text { Peak load } \\
\text { Min-Max (kN) }\end{array}$ \\
Group1 & $20{ }^{\circ} \mathrm{C}$ & 17.78 & 18.65 & 19.05 & 19.98 & 14.07 & 15.15 & 15.01 & 24.22 \\
Group2 & $0{ }^{\circ} \mathrm{C}$ & 16.66 & 17.36 & 17.85 & 18.6 & 14.72 & 15.67 & 15.53 & 25.33 \\
Group3 & $-10{ }^{\circ} \mathrm{C}$ & 14.7 & 15.12 & 15.75 & 16.2 & 15.64 & 16.11 & 15.96 & 26.92 \\
Group4 & $-20{ }^{\circ} \mathrm{C}$ & 14.21 & 14.42 & 15.225 & 15.45 & 15.85 & 16.37 & 16.23 & 27.28 \\
\hline
\end{tabular}

Table 6: Summary of experiment and FEM simulation results for the impact testing specimen.

Fig. 4 represented examples of the effect of the value of GTN parameters on the resulting fracture surface for Charpy specimen, and Fig. 5 shows the simulated impact test and the experimentally tested one. They are in very good agreement. Two faces fracture area can be observed in both pictures.

\section{PrediCT AND ANALYSIS OF INITIATION AND MAXIMUM IMPACT LOADING}

\section{Artificial neural network (ANN)}

7 he fracture simulation by GTN model in Abaqus software provides detailed information and data of the load fracture initiation and propagation in a ductile impact testing specimen.

In this case, the development of ANN application depends on a good selection of training data. In this work, ANN model has been developed to predict the initial and maximum values of loading in impact test at different temperatures. The percentage by weight of GTN parameters was considered as the inputs and the initial and maximum load were considered as the outputs as shown in the Fig. 6. 


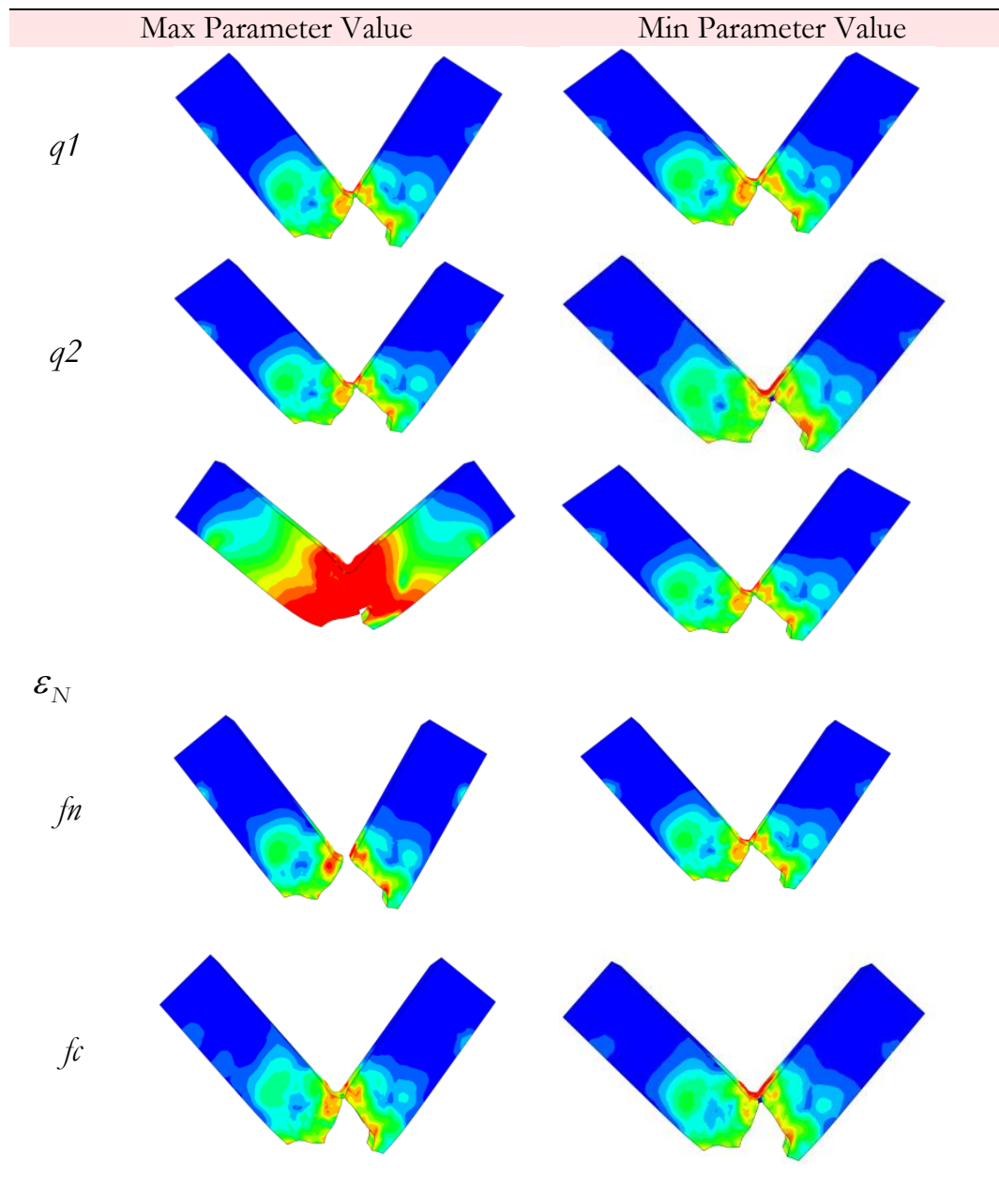

Figure 4: Examples of the effect of the value of GTN parameters on the resulting fracture surface.
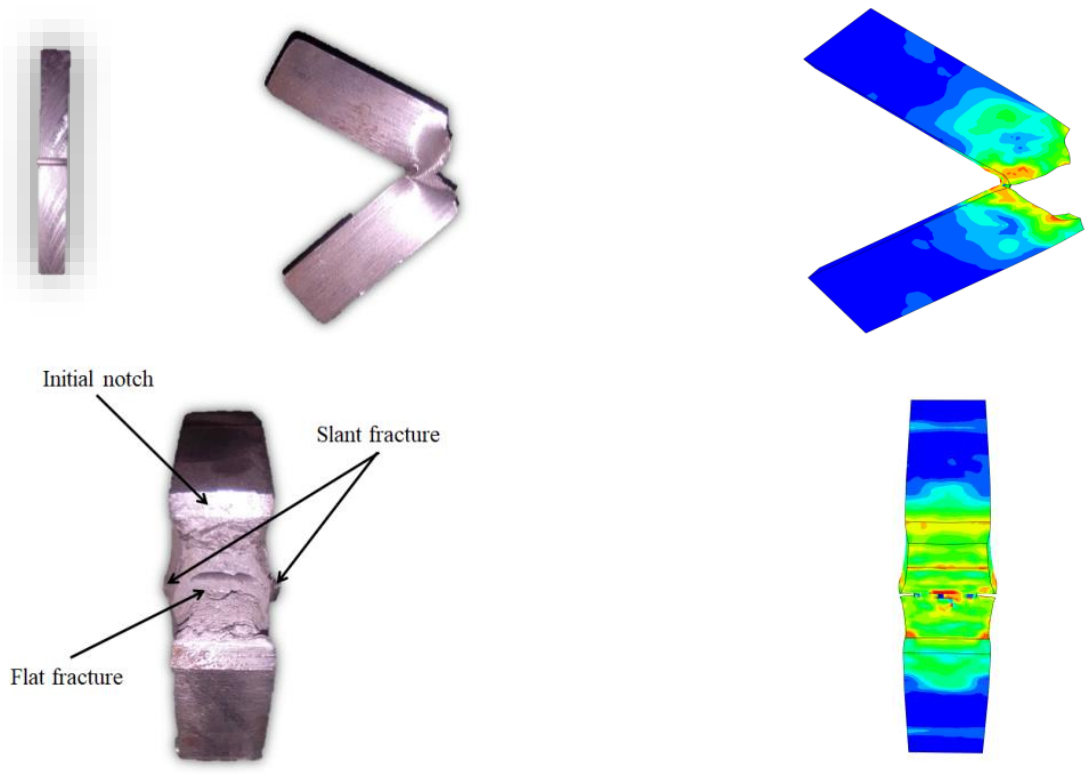

(a)

(b)

Figure 5: The fractured impact testing specimen: tested specimen (a); Simulated specimen (b). 


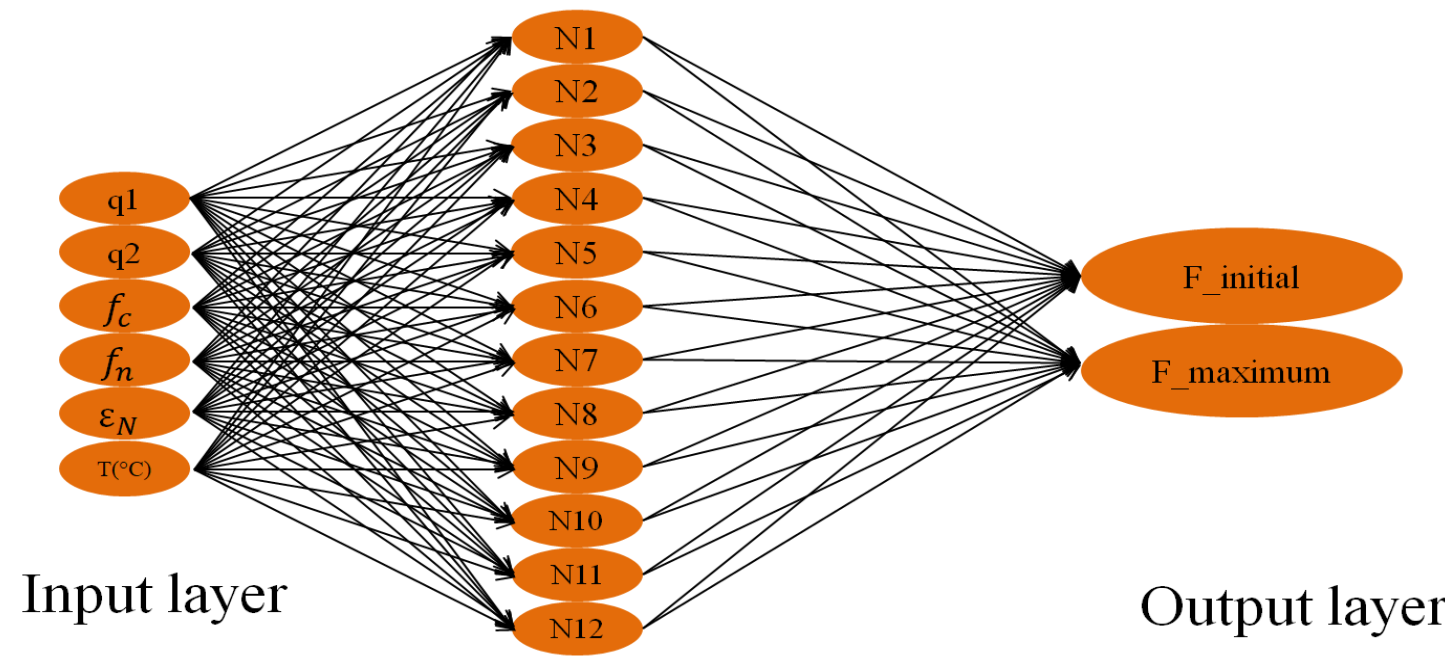

Hidden layer

Figure 6: Architecture of Neural Network.

ANNs have been widely used in several research studies to study the correlation between numerical input data elements and target orientation [14-16]. We try to use ANN to study the relationship and the sensitivity between the GTN parameters and the initial and maximum load for the specimen fracture.

Thus, in our study, the $80 \%$ of the data provided in Tab. 3 is used for training and $20 \%$ for testing and validation of neural networks for the prediction of initial and maximum load at different temperatures. In MATLAB the desired inputs and outputs or targets are imported into the workspace and the network "nntool" is created using inputs and targets. The ANN model has a multi-layered structure, which is connected by nodes with three main layers, namely the input layer (6), the hidden layer (s) (12 neurons) and the output layer ( 2 neurons) as shown in Fig 6 . The mass percentage values of API $\mathrm{X} 70$ steel elements are inputs: $q 1, q 2, \varepsilon_{N}, f n, f c$, and $\mathrm{T}\left({ }^{\circ} \mathrm{C}\right)$. The output layer represents the initial and maximum load values: $F_{\text {initial }}$ and $F_{\text {maximum }}$

The obtained results with the regression analysis (see Fig 7(a)) and performance analysis (see Fig 7(b)) for the prediction of the initial and maximum load values in impact testing at different temperatures of API X70 steel as a function of GTN model parameters are provided using ANN.

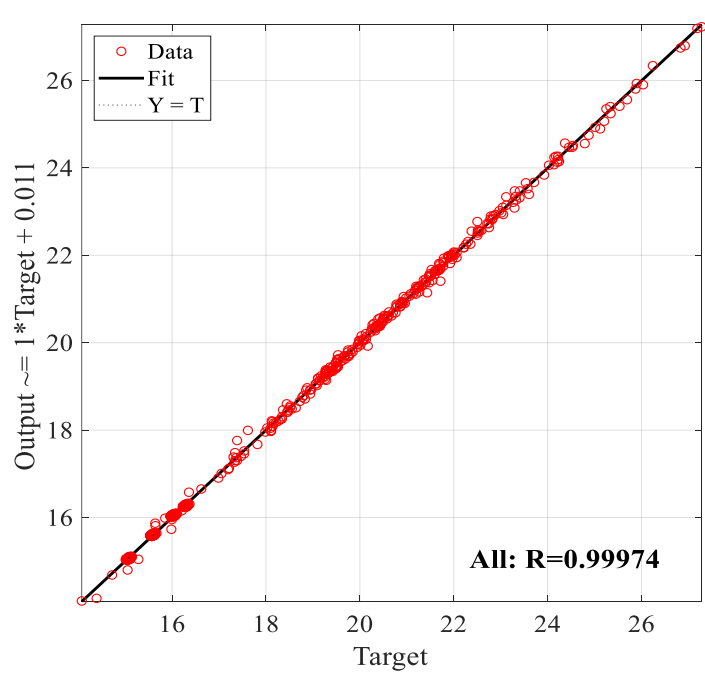

a- Regression analysis

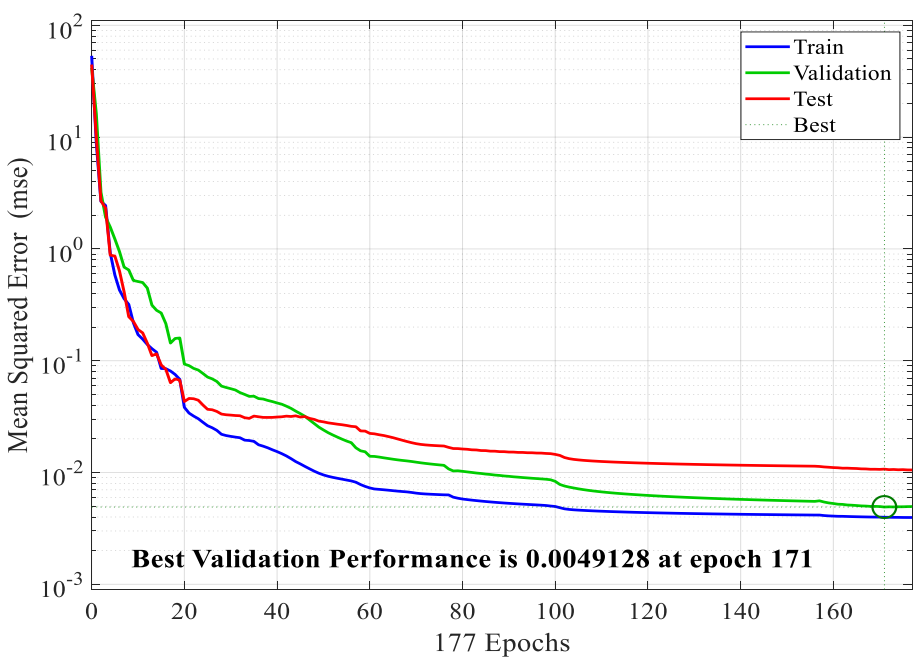

b- Performance analysis

Figure 7: The results obtained for the prediction of initial and maximum load. 
The test input is considered (GTN model parameters) to predict different values of load (initial and maximum) and at different temperatures. The provided results are plotted in Fig. 8 and 9.

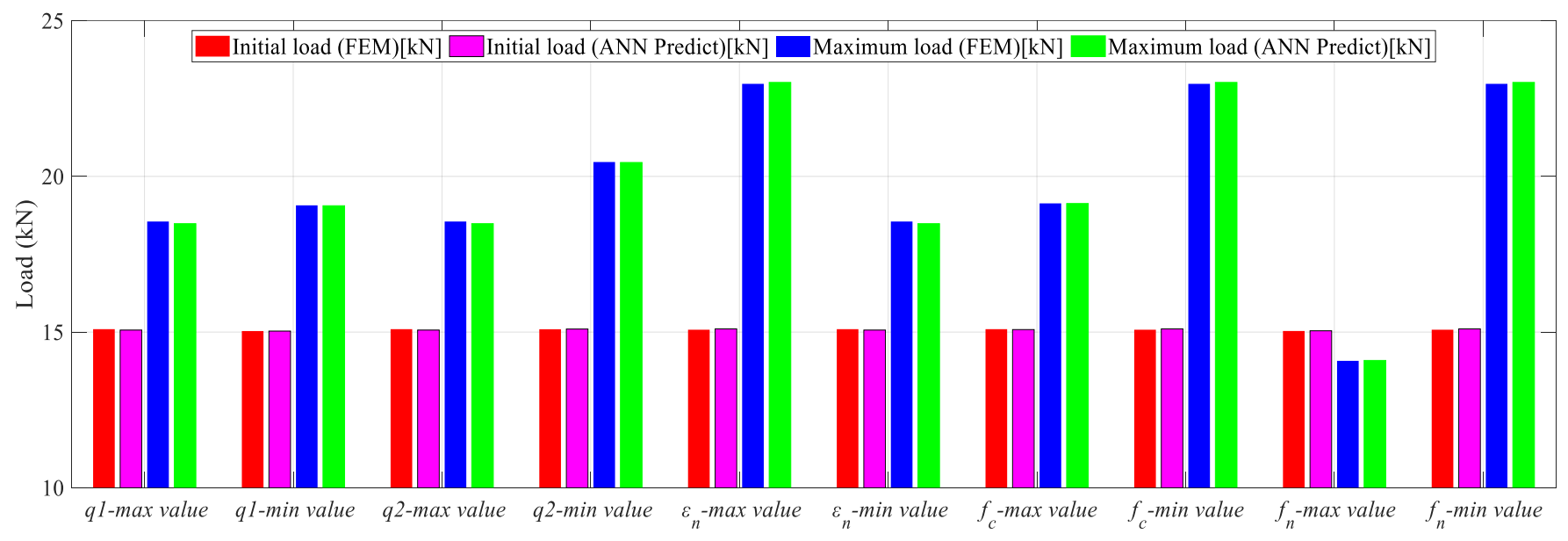

Figure 8: The initial and maximum load with number of parameters GTN model (min and max values).

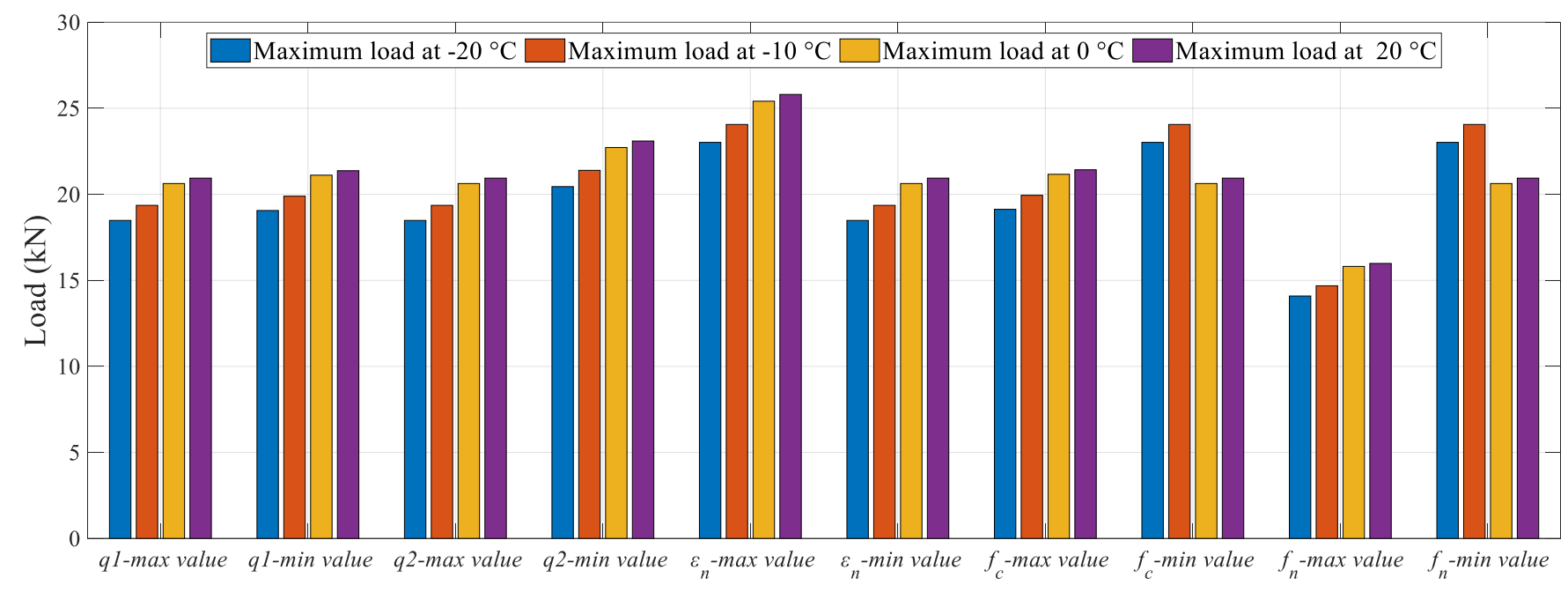

Figure 9: The maximum load at different temperatures and max GTN parameters values of impact testing.

\section{CONCLUSION}

$\mathrm{n}$ artificial neural network model was developed in this work to predict the initial and maximum load and analysis of the GTN damage parameters at different temperatures for dynamic fracture propagation in X70 pipeline steel. Based on the data obtained, the following conclusions can be drawn:

- The calibration of certain parameters requires data and experimental tests and therefore the result of this calibration depends on the latter which varies according to the condition of the tests. So in this work we try to predict and analyze the influences of number GTN parameters on the initial and maximum load and in a temperature range in the Charpy impact test using modelization of neural network which gives better results and makes it possible to minimize the number of simulations.

- From the results, we can say that each GTN model parameter influences the final results by different percent and this allows taking the sensitivity of the parameters in consideration in the calibration part.

- Use of the damage model exists in many studies and researches but the values of the GTN parameters in the calibration of the models are not fixed and equal in them so our study goes through the study of the sensitivity of 
the initial and maximum load in the test of the impact according to the changes of the values of the parameters of the model GTN and in a limited temperature interval.

- The developed model has a great capacity to make the prediction of the results before making calibration and determines the variation between different parameters by the simulation according to the mechanical properties of X70 Steel.

\section{ACKNOWLEDGEMENT}

he third author, Samir Khatir, acknowledges the funding of the postdoctoral fellowship BOF20/PDO/045
provided by Bijzonder Onderzoeksfonds (BOF), Ghent University.

\section{REFERENCES}

[1] Mitchell, E.B., Lucon, E., Collins, L.E., Clarke, A.J., Clarke, K.D. (2021). Microstructure and Thickness Effects on Impact Behavior and Separation Formation in X70 Pipeline Steel, JOM, 73(6), pp. 1966-1977, DOI: $10.1007 / \mathrm{s} 11837-021-04562-9$.

[2] Skalny, P. (2016). Evaluation and Identifying the Ductile Fracture Area of X70 Steel from DWTT Broken Specimens, Procedia Struct. Integr., 2, pp. 3727-3734, DOI: 10.1016/j.prostr.2016.06.463.

[3] Simha, C.H.M., Xu, S., Tyson, W.R. (2015). Computational modeling of the drop-weight tear test: A comparison of two failure modeling approaches, Eng. Fract. Mech., 148, pp. 304-323, DOI: 10.1016/j.engfracmech.2015.06.085.

[4] Mortazavi, E., Najafabadi, R.A., Meysami, A. (2017). Effect of heat input on microstructure and mechanical properties of dissimilar joints of AISI 316L steel and API X70 high-strength low-alloy steel, J. Iron Steel Res. Int., 24(12), pp. 1248-1253, DOI: 10.1016/S1006-706X(18)30024-4.

[5] Cao, Y., Zhen, Y., Song, M., Yi, H., Li, F., Li, X. (2020). Determination of Johnson-Cook parameters and evaluation of Charpy impact test performance for X80 pipeline steel, Int. J. Mech. Sci., 179(August 2019), DOI: $10.1016 /$ j.ijmecsci.2020.105627.

[6] Madhusudhan, D., Chand, S., Ganesh, S., Saibhargavi, U. (2018). Modeling and simulation of Charpy impact test of maraging steel 300 using Abaqus, IOP Conf. Ser. Mater. Sci. Eng., 330(1), DOI: 10.1088/1757-899X/330/1/012013.

[7] Yoon, S.H., Ryu, T.-Y., Kim, M.K., Choi, J.-B., Kim, I.-J. (2019). Development of GTN Model Parameters for Simulating Ductile Fracture Behavior of X 70 Carbon Steel SENT Specimens, ASME 2019 Press. Vessel. Pip. Conf., DOI: 10.1115/PVP2019-93542.

[8] Jang, Y.-Y., Moon, J.-H., Huh, N.-S., Kim, K.-S., Cho, W.-Y., Lee, M.-W., Kim, Y.-J. (2019). Evaluations of Ductile and Cleavage Fracture Using Coupled GTN and Beremin Model in API X70 Pipelines Steel, ASME 2019 38th Int. Conf. Ocean. Offshore Arct. Eng., DOI: 10.1115/OMAE2019-96483.

[9] Gholipour, H., Biglari, F.R., Nikbin, K. (2019). Experimental and numerical investigation of ductile fracture using GTN damage model on in-situ tensile tests, Int. J. Mech. Sci., 164, pp. 105170, DOI: 10.1016/j.ijmecsci.2019.105170.

[10] Kim, J.-S., Kim, Y.-J., Lee, M.-W., Kim, K.-S., Shibanuma, K. (2020). Fracture simulation model for API X80 Charpy test in Ductile-Brittle transition temperatures, Int. J. Mech. Sci., 182, pp. 105771, DOI: $10.1016 /$ j.ijmecsci.2020.105771.

[11] Rahman, K.M.M., Mohtadi-Bonab, M.A., Ouellet, R., Szpunar, J. (2019). A Comparative Study of the Role of Hydrogen on Degradation of the Mechanical Properties of API X60, X60SS, and X70 Pipeline Steels, Steel Res. Int., 90(8), pp. 1900078, DOI: 10.1002/srin.201900078.

[12] Raafat, E., Nassef, A., El-hadek, M., El-Megharbel, A. (2019). Fatigue and thermal stress analysis of submerged steel pipes using ANSYS software, Ocean Eng., 193(October), pp. 106574, DOI: 10.1016/j.oceaneng.2019.106574.

[13] Carla Silva de Araújo, L., Cândido, L.C., Trindade, V.B., Porcaro, R.R. (2017). Evaluation of the influence of post welding heat treatments on microstructure and mechanical properties of API 5L X70Q weld joints, Weld. Int., 31(4), pp. 251-258, DOI: 10.1080/09507116.2016.1218609.

[14] Hojjat, G., Shahram, S., Mohammad, S. (2020). Predicting the Burst Pressure of High-Strength Carbon Steel Pipe with Gouge Flaws Using Artificial Neural Network, J. Pipeline Syst. Eng. Pract., 11(4), pp. 4020034,

DOI: $10.1061 /$ (ASCE)PS.1949-1204.0000478.

[15] Abarghouee, H., Arabi, H., Seyedein, S.H., Mirzakhani, B. (2021). Modelling of hot flow behavior of API-X70 
microalloyed steel by genetic algorithm and comparison with experiments, Int. J. Press. Vessel. Pip., 189, pp. 104261, DOI: $10.1016 /$ j.ijpvp.2020.104261.

[16] Ouladbrahim, A., Belaidi, I., Khatir, S., Magagnini, E., Capozucca, R., Wahab, M.A. (2021). Prediction of Gurson Damage Model Parameters Coupled with Hardening Law Identification of Steel X70 Pipeline Using Neural Network, Met. Mater. Int., DOI: 10.1007/s12540-021-01024-4. 